\title{
O ELASTECIMENTO JURISPRUDENCIAL DO ALCANCE DA CASSAÇÃO DE TERCEIROS EM RAZÃO DE FRAUDE À QUOTA DE GÊNERO E SUAS CONSEQUÊNCIAS
}

\author{
The Jurisprudential Enlargement of the Reach of Third Party Cassacy as a Result for \\ Frand to the Gender Quota and its Consequences
}

Henrique Kurscheidt

Resumo: O presente artigo tem por objetivo examinar as possíveis consequências na prática eleitoral do entendimento recentemente estabelecido pelo Tribunal Superior Eleitoral (TSE), quando do julgamento do REspe 193-92/PI, segundo o qual a constatação da existência de uma única candidatura feminina fraudulenta em sede de Aije leva necessariamente à cassação do registro ou diploma de todos os demais integrantes da legenda ou coligação no pleito proporcional, visando responder se a ampliação do alcance da cassação de terceiros atende ao louvável intuito de dar máxima efetividade à ação afirmativa que se pretende implementar por meio das quotas de gênero ou, na prática, poderá levar à situação fática oposta àquela que se pretendeu prestigiar com a instituição de tal sistemática e impor restrições ainda mais severas ao ingresso e efetiva participação das mulheres na vida política do País.

Palavras-chave: Direito eleitoral. Quotas de gênero. Candidatura "laranja". Ação de Investigação Judicial Eleitoral. Terceiros beneficiados.

\begin{abstract}
This article examines possible consequences on the implementation of the recent decision of the Superior Electoral Court of Brazil in the judgment of REspe 19392/PI. According to the judgment, a single fraudulent female candidacy, discussed in an investigation by the electoral justice (AIJE), should lead to revoking the registration and confirmation of all the other members of an elected party or coalition. The understanding seeks to establish the scope of the acts revoking undue benefits resulting from fraud, reaching third parties even if not directly involved. The intention is to offer maximum effectiveness to the affirmative action of gender quotas, preventing the misuse of the system that could jeopardize women's participation in Brazil's political life.
\end{abstract}

Keywords: Electoral law. Gender quotas. Fraudulent application. Electoral judicial investigation action. Benefited third parties.

Artigo recebido em 10 jun. 2020 e aprovado em 21 out. 2020. 


\section{Introdução}

A representação política é historicamente marcada por acentuada desigualdade de gênero, que decorre, dentre outros fatores, da tardia admissão das mulheres na vida política e da misoginia que ainda impregna parte de nossa sociedade e instituições.

Embora não se trate de fenômeno exclusivamente brasileiro, tal desigualdade é especialmente acentuada no Brasil, onde o voto feminino somente foi plenamente equiparado ao voto masculino em 1946, quando se tornou obrigatório (embora tenha sido inicialmente admitido, em caráter facultativo, com o advento do Código Eleitoral de 1932) e o percentual de mulheres ocupando cargos políticos é bastante reduzido.

Para reverter esse quadro e estimular a inserção feminina na política, foram instituídas, a partir de 1995, quotas eleitorais de gênero, exigindo-se dos partidos políticos a observância de percentual mínimo de candidaturas de cada sexo nas eleições proporcionais, sendo exigido, atualmente, o preenchimento de no mínimo 30\% (trinta por cento) e no máximo $70 \%$ (setenta por cento) para candidaturas de cada sexo, na forma do art. 10, § $3^{\circ}$, da Lei 9.504/1997, com a redação que lhe foi dada pela Lei 12.034/2009.

Contudo, a ação afirmativa tem tido sua efetividade comprometida pela adoção de expediente fraudulento que se tornou conhecido como candidatura "laranja", que consiste no lançamento de candidaturas femininas fictícias, registradas apenas para preenchimento da quota eleitoral de gênero, com candidatas que não participarão efetivamente do pleito e que, por vezes, sequer sabem que foram registradas para disputar as eleições. Como resultado, tem-se, a cada pleito, um expressivo número de candidaturas femininas que obtém votação inexpressiva ou, por vezes, não recebem sequer um único voto.

Para possibilitar o combate efetivo a essa prática, a jurisprudência eleitoral, amparada no caráter instrumental do processo e na natureza coletiva da tutela jurídico-eleitoral, tem gradativamente ampliado o alcance das ações eleitorais típicas, tendo inicialmente estendido o conceito de fraude passível de apuração por meio de Ação de Impugnação ao Mandato Eletivo (Aime) para nele enquadrar a fraude à quota de gênero e, mais recentemente, passado a admitir, também, o manejo de Ação de Investigação Judicial Eleitoral (Aije) para apuração dessa espécie de fraude. 
Para além do caráter processual, a ampliação das hipóteses de cabimento da Aije para análise da fraude à quota de gênero tem importante consequência material, tendo em vista que, nessa espécie de ação, a sentença de procedência atrai a incidência das penalidades previstas no inciso XIV, do art. 22, da LC 64/1990, com a declaração de inexigibilidade nos oito anos subsequentes ao pleito de todos aqueles que tenham contribuído para a prática do ato e cassação do registro ou diploma dos candidatos diretamente beneficiados.

O Tribunal Superior Eleitoral (TSE) recentemente se manifestou acerca do tema, quando do julgamento do Recurso Especial Eleitoral (REspe) $n^{\circ}$ 193-92/PI, em 17 de setembro de 2019, estabelecendo a extensão e natureza da sanção decorrente do reconhecimento da fraude às quotas de gênero em sede de Ação de Investigação Judicial Eleitoral, consolidando o entendimento da Corte Eleitoral no sentido de que a inelegibilidade é sanção personalíssima e aplicável somente em face daqueles que cometeram, participaram ou anuíram com a prática fraudulenta, mas, que, por outro lado, todos os demais candidatos do partido ou coligação ${ }^{1}$ no pleito proporcional devem ser considerados beneficiários da fraude, com a consequente cassação de seus registros ou diplomas, independentemente da existência de provas de que tenham participado ou anuído com o ardil.

O presente estudo tem por objetivo perquirir se a sistemática instituída pelo TSE, a partir do precedente mencionado acima, segundo a qual a constatação da existência de uma única candidatura feminina fraudulenta em sede de Aije leva necessariamente à cassação do registro ou diploma de todos os demais integrantes da legenda ou coligação no pleito proporcional, atende ao louvável intuito de dar efetividade à ação afirmativa que se pretende implementar por meio das quotas de gênero ou, na prática, poderá levar à situação fática oposta àquela que se pretendeu prestigiar com a instituição de tal sistemática e impor restrições ainda mais severas ao ingresso e efetiva participação das mulheres na vida política do País.

Em tal análise, buscou-se realizar ampla revisão bibliográfica acerca do objeto de estudo, orientado pelo método indutivo e estruturado em cinco capítulos, iniciando-se, no primeiro capítulo, com uma análise da atual sub-representação política feminina e suas causas; no segundo capítulo, é apresentado o instituto das quotas eleitorais de gênero e sua gradativa

\footnotetext{
${ }^{1}$ A possibilidade de coligações em pleitos proporcionais foi suprimida pela Emenda Constitucional no 97/2017.
} 
evolução no direito eleitoral brasileiro; no terceiro, é examinada a fraude à quota de gênero; no quarto capítulo, as ações eleitorais cabíveis para enfrentamento da fraude e suas diferentes consequências são analisadas e, no quinto e último, são expostos os argumentos contrários ao elastecimento jurisprudencial do alcance da cassação de terceiros em razão da fraude à quota de gênero. Por fim, em conclusão, são apresentadas possíveis alternativas para o tratamento da matéria.

\section{A sub-representação política feminina e suas causas}

O exercício da cidadania e a participação do cidadão na vida política do Estado, por meio do voto, remonta à democracia ateniense, datada do século $\mathrm{V}$ a.C., na qual se compreendia o regime democrático como "o governo realizado por todos os cidadãos, entre os quais não se incluíam os escravos e as mulheres" (RUSSELL, 2015, 1. 520). Nos Estados Modernos, o direito ao sufrágio foi consolidado e ampliado nos séculos XVII e XVIII, notadamente pelas experiências inglesa, francesa e, sobretudo, norte-americana.

A participação feminina na vida política, contudo, é muito mais recente e fruto de um longo e gradual processo de evolução histórica, conquistada a duras penas pelo movimento feminista, que se desenvolve como movimento de emancipação da mulher, iniciado na Inglaterra e que se estende aos demais países europeus a partir do século XIX, tendo a luta pelo direito ao voto feminino com um de seus principais estandartes (BOBBIO, 1991, p. 488).

$\mathrm{Na}$ América Latina, o processo de admissão do sufrágio feminino tem início em 1929, no Equador, e se encerra somente em 1961, com a implementação do voto feminino no Paraguai e Uruguai (SANTOS; BARCELOS; GRESTA, 2019, p. 25).

No Brasil, embora o primeiro partido político de orientação declaradamente feminista tenha sido fundado em 1910 (o Partido Republicano Feminino), o voto feminino somente foi instituído em 1927, inicialmente apenas no Rio Grande do Norte, mediante reforma da Constituição daquele Estado. Em âmbito nacional, apenas com o advento do Código Eleitoral de 1932 foi admitida a candidatura de mulheres e o voto feminino, este último inicialmente de caráter facultativo, em contraposição à obrigatoriedade do voto masculino, que se encerrava somente aos 60 anos de idade. Posteriormente, em 1946, a legislação foi alterada, tornando obrigatório o voto feminino. 
Como resultado desse descompasso histórico e da misoginia que ainda impregna parte de nossa sociedade e instituições, a representação política é atualmente marcada por acentuada desigualdade de gênero.

Consoante estatísticas divulgadas pelo Tribunal Superior Eleitoral, nas eleições gerais de 2018, embora quase 32\% (trinta e dois por cento) das candidaturas tenham sido de mulheres (com 9.204 candidatas do sexo feminino para 19.881 candidatos do sexo masculino) $)^{2}$, o percentual de representantes do sexo feminino eleitas foi de apenas 16\% (dezesseis por cento), com a conquista de 290 vagas dos 1.790 cargos em disputa ${ }^{3}$. Em estudo comparativo, divulgado em 2017, pela Organização das Nações Unidas (ONU) em parceria com a União Interparlamentar (UIP), o Brasil figurou na $154^{a}$ posição em ranking de 174 países acerca da participação das mulheres no Congresso, com representantes femininas ocupando 55 das 513 cadeiras da Câmara (10,7\%) e 12 das 81 vagas do Senado $(14,8 \%)^{4}$.

\section{As quotas eleitorais de gênero}

Visando reduzir a desigualdade de gênero na representação política e promover a inserção feminina, em 1995, foi editada a Lei 9.100, que instituiu, pela primeira vez no direito brasileiro, quotas eleitorais de gênero, prevendo, em seu art. 11, \3을 que: "vinte por cento, no mínimo, das vagas de cada partido ou coligação deverão ser preenchidas por candidaturas de mulheres".

Posteriormente, o percentual da quota de gênero foi ampliado pela Lei das Eleições (Lei 9.504/1997), que passou a exigir um percentual mínimo de 30\% (trinta por cento) e máximo de 70\% (setenta por cento) para cada sexo (art. 10, \ $3^{\circ}$ ). A redação original do art. 10, \3을 da Lei 9.504/97 estabelecia que cada partido deveria reservar o percentual mínimo de candidaturas por gênero, que poderia ou não ser preenchido, de forma que, caso o percentual mínimo não fosse atingido por um dos gêneros, bastava ao partido político ou coligação lançar um número menor de candi-

\footnotetext{
${ }^{2}$ Disponível em: < http://www.tse.jus.br/eleicoes/estatisticas/estatisticas-eleitorais>.

3 Disponível em: <http://www.tse.jus.br/imprensa/noticias-tse/2019/Marco/numero-de-mulheres-eleitas-em-2018-cresce-52-6-em-relacao-a-2014>.

${ }^{4}$ Disponível em: <https://www.ipu.org/resources/publications/infographics/2017-03/ women-in-politics-2017?utm_source=Inter-Parliamentary+Union+\%28IPU\%29\&utm_ campaign=550dedbec7-MAIL_CAMPAIGN_2017_02_23\&utm_medium=email\&utm_ term=0_d1ccee59b3-550dedbec7-258891957>.
} 
datos do que aquele permitido pelo art. 10, caput, da Lei 9.504/1997 (150\% das vagas em disputa), sem efetivamente preencher o percentual mínimo de gênero.

Finalmente, com a edição da Lei 12.034, em 2009, conhecida como primeira minirreforma eleitoral, tornou-se impositivo o preenchimento da quota mínima de gênero, tendo sido alterada a redação do art. $10, \sqrt{ } 3^{\circ}$ da Lei 9.504/1997 que passou a prever que "cada partido ou coligação preencherá o mínimo de 30\% (trinta por cento) e o máximo de $70 \%$ (setenta por cento) para candidaturas de cada sexo", substituindo-se a locução "deverá reservar" por "preencherá".

Assim, nos termos da legislação eleitoral em vigor, independentemente da utilização do número máximo de candidaturas, no mínimo 30\% (trinta por cento) das candidaturas efetivamente lançadas por cada partido político deverão ser preenchidas por mulheres, sob pena de indeferimento do Demonstrativo de Regularidade dos Atos Partidários (DRAP) apresentado pelo partido político, com o consequentemente indeferimento do registro de todas as candidaturas a ele vinculadas (SANTOS, BARCELOS e GRESTA, 2019, p. 29).

\section{Das candidaturas femininas fraudulentas}

Em que pese a progressiva instituição de incentivos legais à participação feminina na política, os avanços na almejada superação do quadro de sub-representação política das mulheres ainda são tímidos, conforme estatísticas mencionadas acima.

Além dos fatores históricos e culturais que dificultam a igualdade de gênero na política, a reduzida efetividade do sistema de quotas se deve, também, à frequente utilização de expediente fraudulento consistente no lançamento das chamadas candidaturas femininas "laranjas", destinadas a apenas preencher o percentual mínimo de gênero, sem que sejam realizados quaisquer esforços para que tais candidatas sejam efetivamente eleitas, não sendo realizada campanha política, gastos eleitorais ou pedido de votos e, por vezes, com a candidata "laranja" se engajando abertamente em campanha política de candidato concorrente; não sendo incomum, nesse contexto, que parte das candidaturas femininas não obtenha sequer um único voto, evidenciando seu caráter fraudulento. 
Nesse sentido, o Tribunal Superior Eleitoral apurou que, em 2016, dos 16.000 candidatos que terminaram a eleição sem ter recebido nenhum voto, 14.417 eram mulheres e apenas 1.714 eram homens (LEITE; GUNDIM, p. 152), a indicar que grande parte das candidaturas nessa situação havia sido lançada para preenchimento fraudulento da quota de gênero.

\section{Dos meios de impugnação à candidatura feminina fraudulenta e suas consequências}

A observância dos percentuais mínimos de gênero, previstos no art. 10, \3ㅜ da Lei 9.504/97, constitui matéria a ser verificada, ordinariamente, nos autos do Demonstrativo de Regularidade de Atos Partidários (DRAP), também conhecido como "processo raiz" e que constitui a fase inicial do processo de registro de candidaturas, no qual é averiguada a regularidade das situações exigidas para participação da agremiação política na disputa eleitoral e que, sendo deferido, permite a apreciação individualizada dos pedidos de registro de cada candidato, evitando a repetição da análise da regularidade partidária e a prolação de decisões conflitantes a esse respeito (LACERDA; LUCENA, 2018, p. 23). Nessa fase, consoante firme entendimento do TSE, é admissível a regularização do percentual de gênero mesmo após a prolação de sentença de $1^{\circ}$ grau, durante a fase recursal ${ }^{5}$.

No entanto, como regra, o caráter fraudulento da candidatura feminina lançada para mero preenchimento das quotas de gênero é constatado apenas em momento posterior do processo eleitoral, tendo em vista que somente durante a campanha e na apuração dos resultados é possível verificar se foram envidados efetivos esforços para o êxito da candidatura, se a candidata obteve uma quantia mínima de votos e se eventualmente se engajou na campanha de candidatos concorrentes, em detrimento de sua própria candidatura. Por este motivo, o Tribunal Superior Eleitoral passou a admitir o manejo da Ação de Impugnação ao Mandato Eletivo (Aime), prevista no art. 14, \10, da Constituição Federal, para apuração dessa espécie de ardil, superando anterior entendimento no sentido de que a fraude a ser apurada em sede de Aime seria somente aquela diretamente relacionada ao processo de votação e passando a considerar que "O termo fraude, estampado no art. 14, \10, da Constituição Federal, encerra conceito aberto,

\footnotetext{
5 Tribunal Superior Eleitoral. Recurso Especial Eleitoral noำ 286-25, Decisão Monocrática, relatora min. Fátima Nancy Andrighi. Sessão em 02 out. 2012.
} 
a englobar todas as situações de fraude - inclusive a de fraude à lei - que possam afetar a normalidade das eleições e a legitimidade do mandado obtido" , ampliando, assim, as hipóteses de cabimento da referida ação eleitoral, inclusive para apurar a prática de fraudes no preenchimento das quotas de gênero.

Posteriormente, consolidou-se, também, no âmbito jurisprudencial, a possibilidade dessa espécie de fraude ser objeto de Ação de Investigação Judicial Eleitoral (Aije), prevista no art. 22 da Lei Complementar 64/1990 e que tem por escopo coibir o "uso indevido, desvio ou abuso do poder econômico ou do poder de autoridade, ou utilização indevida de veículos ou meios de comunicação social, em benefício de candidato ou de partido político", mitigando-se, em alguma medida, o princípio da tipicidade das ações eleitorais, diante da necessidade de antecipar e garantir a apreciação jurisdicional de tais situações, em prol da normalidade e legitimidade dos pleitos.

A admissão da Aije para tratamento da matéria veio preencher verdadeiro "vácuo na apreciação jurisdicional" a respeito do tema, tendo em vista que, conforme exposto alhures, o caráter fraudulento das candidaturas "laranja" somente resta evidenciado em momento posterior à análise do DRAP, que ocorre no início do processo eleitoral, e a Aime, por sua vez, somente pode ser proposta após o decurso de grande lapso temporal, ao final do pleito, nos 15 dias posteriores à diplomação e apenas em desfavor de candidato que tenha obtido mandato eletivo apto a ser impugnado ${ }^{7}$, de forma que, caso não se admitisse o manejo da Aije para enfrentamento da matéria, não seria possível apurar a fraude nas hipóteses em que seus autores não obtivessem êxito no processo eleitoral, em ofensa ao princípio da inafastabilidade da jurisdição (art. 5ª, XXXV, da CF/88).

Para possibilitar o exame das fraudes à quota de gênero em sede de Aije e enquadrar a matéria dentre as hipóteses de cabimento de tal ação eleitoral, o Tribunal Superior Eleitoral, amparado no caráter instrumental do processo e na natureza coletiva da tutela jurídico-eleitoral, enquadrou o expediente fraudulento como abuso de poder dos partidos políticos, ou seja, que "o abuso de poder a que se referem os arts. 19 a 22 da LC 64/90

\footnotetext{
${ }^{6}$ Tribunal Superior Eleitoral. Recurso Especial Eleitoral nํㅜ 149, acórdão, relator min. Henrique Neves da Silva, DJE - Diário de justiça eletrônico de 21 out. 2015.

7 Tribunal Superior Eleitoral, Recurso Especial Eleitoral no 52431, acórdão, relator min. Luiz Fux, AC. Sessão de 16 jun. 2016.
} 
deve ser compreendido de forma ampla, albergando condutas fraudulentas e contrárias ao ordenamento jurídico-eleitoral" e que "a fraude nada mais é do que espécie do gênero abuso de poder"8.

Tal entendimento, para além de permitir o enfrentamento do tema em sede de Aije, tem importante reflexo no que tange às consequências do reconhecimento judicial da fraude, eis que o enquadramento do ato como abuso de poder atrai a aplicação das sanções previstas no inciso XIV, do art. 22, da LC 64/1990, segundo o qual, julgada procedente a representação, será declarada a "inelegibilidade do representado e de quantos hajam contribuído para a prática do ato", que se estenderá pelos oito anos subsequentes ao pleito, além de ser cassado "o registro ou diploma do candidato diretamente beneficiado".

Não se trata, portanto, de questão meramente instrumental, existindo relevante consequência material, decorrente do enquadramento da fraude como abuso de poder, passível de ser objeto de apuração judicial por meio de Aije, no aspecto da severidade e extensão da sanção decorrente do ato fraudulento. Isto porque, sendo julgada procedente a Aije e aplicando-se o inciso XIV, do art. 22, da LC 64/90, todos aqueles que tenham contribuído para a prática do ato serão declarados inelegíveis nos oito anos subsequentes ao pleito e os candidatos diretamente beneficiados pela fraude terão seu registro ou diploma cassados. Por outro lado, apurando-se a fraude em sede de Aime, o polo passivo da ação, de regra, será composto unicamente pelo candidato regularmente diplomado e a procedência da ação terá como único desdobramento a cassação do diploma obtido pelo requerido, não sendo cabível, no âmbito de tal ação eleitoral, a aplicação da sanção de inelegibilidade ${ }^{9}$ ou a punição de eventuais terceiros beneficiados pelo ilícito eleitoral.

A extensão e natureza da sanção decorrente do reconhecimento da fraude às quotas de gênero em sede de Aije foi objeto de questionamento perante o Tribunal Superior Eleitoral, por meio do Recurso Especial Eleitoral no 193-92/PI, de relatoria do ministro Jorge Mussi, tendo sido proferida recente decisão que consolidou o entendimento da Corte Eleitoral a esse respeito, no sentido de que a inelegibilidade é sanção persona-

\footnotetext{
${ }^{8}$ Tribunal Superior Eleitoral, Recurso Especial Eleitoral nº 63184, acórdão, relator min. Luiz Fux, Diário de Justiça Eletrônico - DJE, de 05 out. 2016.

${ }^{9}$ Tribunal Superior Eleitoral, AgR-REspe no 118232 , acórdão, relator min. Gilmar Mendes. Sessão de 05.02.2015.
} 
líssima e aplicável apenas em face daqueles que cometeram, participaram ou anuíram com a prática fraudulenta, mas, que, por outro lado, todos os demais candidatos do partido ou coligação ${ }^{10}$ no pleito proporcional devem ser considerados beneficiários da fraude, com a consequente cassação de seus registros ou diplomas, independentemente da existência de provas de que tenham participado ou anuído com o ardil.

Assim, constata-se que, atualmente, a fraude às quotas de gênero pode ser objeto de apuração judicial em três diferentes momentos do processo eleitoral - na fase inicial de análise do DRAP, durante a campanha por meio de Aije ou após a diplomação em sede de Aime - e suas consequências variam a depender do momento em que são apuradas e da via processual eleita pelo autor da ação para submeter o fato à apreciação jurisdicional.

\section{Dos argumentos contrários ao elastecimento do alcance da cassação de terceiros em razão da fraude à quota de gênero}

Embora o intuito de dar máxima efetividade à ação afirmativa que se pretende implementar por meio das quotas de gênero certamente seja louvável, a sistemática instituída pelo TSE, quando do julgamento do Recurso Especial Eleitoral 193-92/PI, segunda a qual a constatação da existência de uma única candidatura feminina fraudulenta em sede de Aije leva necessariamente à cassação do registro ou diploma de todos os demais integrantes da legenda ou coligação no pleito proporcional, é passível de críticas e questionamentos acerca de seus resultados na prática eleitoral, sendo possível que venha a promover situação fática oposta àquela que se pretendeu prestigiar com a instituição de tal sistemática e impor restrições ainda mais severas ao ingresso e efetiva participação das mulheres na vida política do País.

Para além da óbvia consequência da ampla cassação poder atingir também mulheres regularmente eleitas e que não tenham tido qualquer participação no $\operatorname{ardil}^{11}$, a sistemática instituída pela TSE torna desaconselhável

10 A possibilidade de coligações em pleitos proporcionais foi suprimida pela Emenda Constitucional $n^{\circ}$ 97/2017.

${ }^{11}$ Como, inclusive, ocorreu no precedente em questão, em que a ampla cassação levou à perda do mandato de duas candidatas (Maria de Fátima Bezerra e Ariana Maria de Carvalho) que haviam sido regularmente eleitas e que não haviam participado ou tinham conhecimento comprovado da fraude. 
aos partidos políticos permitir o ingresso em sua lista de candidatos de representantes do sexo feminino que tenham pouca ou nenhuma experiência política, tendo em vista que, caso posteriormente se revele que a candidata não tinha condições ou mesmo a efetiva intenção de viabilizar minimamente sua candidatura, o partido político poderá sofrer a severa sanção de cassação de todos os demais integrantes de sua lista de candidatos, em grave prejuízo à representação política da corrente de pensamento ou ideologia adotada pela agremiação e seus eleitores durante a legislatura subsequente ao pleito.

Ante a gravidade da sanção e de seus amplos efeitos no resultado das eleições, não é possível descartar sequer a possibilidade de que, doravante, candidatas "laranjas" venham ser ardilosamente plantadas nas listas de partidos políticos adversários ou cooptadas durante o pleito pelas agremiações concorrentes para abandonar a campanha política, com o intuito de restar caracterizada a fraude às quotas de gênero, com a consequente cassação de todas as candidaturas de determinado partido político e destinação das cadeiras obtidas no pleito a seus concorrentes.

Constata-se, portanto, que, com a sistemática instituída pelo TSE no julgamento do REspe 193-92/PI, o lançamento de candidaturas femininas, sobretudo de candidatas que concorrem pela primeira vez e que não sejam previamente conhecidas pelos órgãos de direção do partido político, torna-se conduta arriscada e potencialmente danosa às pretensões políticas da agremiação no pleito. Tal cenário cria um estímulo para que os partidos políticos, visando minimizar riscos, lancem somente candidaturas de representantes do sexo feminino já conhecidas e experientes e que cada nova pré-candidata seja submetida a rigoroso escrutínio acerca de suas motivações e da viabilidade de sua candidatura, antes de ser aceita pela agremiação política. Com isso, tem-se que, na prática, as mulheres acabarão sendo submetidas a requisito não exigido dos candidatos do sexo masculino, criando-se considerável obstáculo ${ }^{12}$ para o ingresso das mulheres na política e para a formação de novas lideranças femininas; quadro esse, que, certamente, vai de encontro aos fins das quotas de gênero.

Não se pode deixar de considerar, também, que o enquadramento jurisprudencial da fraude às quotas de gênero como abuso de poder passí-

\footnotetext{
${ }^{12}$ Há que se considerar que, na fase de escolha dos candidatos, a viabilidade da candidatura, notadamente em se tratando de candidata que concorre pela primeira vez, é de difícil comprovação.
} 
vel de ser apreciado em sede de Aije é resultado de elastério hermenêutico norteado por questão de cunho eminentemente instrumental e destinado a suprir "vácuo jurisdicional" no enfrentamento da matéria, ante a constatação da existência de grande lapso temporal entre a análise do DRAP e a fase de impugnação ao mandato eletivo, sem que exista outro mecanismo processual apto a apurar a fraude nesse interregno.

No entanto, embora o aspecto processual da admissibilidade da ação eleitoral possa ser norteado por essa lógica instrumental, é certo que a aplicação das sanções decorrentes da conduta fraudulenta deve ser regida por lógica diversa e adstrita aos postulados restritivos do direito eleitoral sancionador, sujeito, dentre outros, ao princípio da legalidade estrita. Assim, por se tratar de norma de caráter sancionador e restritiva de direitos, não se pode, por meio de interpretação extensiva, ampliar o alcance das sanções previstas no art. 22, XIV, da LC 64/1990 para atingir terceiros que não tenham contribuído para a prática do ato fraudulento ou obtido benefício direto com sua prática.

Como visto, nos termos do art. 22, XIV, da LC 64/90, aqueles que tenham contribuído para a prática do ato estão sujeitos à sanção de inelegibilidade e os terceiros beneficiários do ato à cassação do registro ou diploma. A conceituação e identificação dos participantes do ato fraudulento, sujeitos à pena de inelegibilidade, não demanda grande esforço hermenêutico. Por outro lado, a identificação dos terceiros beneficiários, passíveis de ter cassado o registro ou diploma, guarda maior complexidade, sendo necessário considerar, em tal análise, que a norma restringe seu alcance ao "candidato diretamente beneficiado pela interferência do poder econômico pelo desvio ou abuso do poder" (negritei e sublinhei). Ou seja, para que a cassação possa ser aplicada em desfavor de terceiro não participante do ato, não basta que se possa inferir a existência de potencial benefício reflexo ou indireto, sendo imprescindível que do ato fraudulento decorra comprovado benefício direto à candidatura do terceiro.

Ao decidir pela aplicação da cassação a todos os integrantes da legenda em que constatada fraude à quota de gênero, o TSE considerou que, nesse caso, o benefício decorrente da fraude seria caracterizado pela possibilidade de registro de um maior número de candidatos homens, cujos votos seriam computados em favor da agremiação, com reflexo favorável no quociente partidário, permitindo a conquista de um maior número de mandatos pelo partido e que a eventual cassação apenas dos registros dos 
candidatos do sexo masculino excedentes à quota de gênero não solucionaria a distorção, pois, segundo o entendimento que prevaleceu quando do julgamento do REspe 193-92/PI ${ }^{13}$, por força da disposição contida no art.

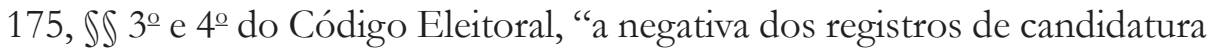
somente após a data do pleito (...) implica no aproveitamento dos votos em favor das coligações, evidenciando-se, mais uma vez, o inquestionável benefício auferido com a fraude".

Com a devida vênia, quer nos parecer que, se efetivamente existe benefício na hipótese, ele caracteriza, no máximo, favorecimento indireto ao demais candidatos do partido político, que não podem ser considerados diretamente beneficiados pela prática do ato, tal como exige o art. 22, XIV, da LC 64/1990, para que possa ser aplicada a cassação do registro ou diploma democraticamente obtido.

Como bem observado pelo ministro Og Fernandes, no voto vencido que proferiu no julgamento do REsp 193-92/PI, o potencial benefício obtido com a fraude de gênero é significativamente diverso daquele que decorre da prática das condutas expressamente previstas pelo legislador como hipóteses típicas de cabimento da Aije, cujos efeitos impactam de maneira inequívoca o mundo empírico, afetando de forma direta seu resultado e impedindo que o candidato beneficiado alegue real desconhecimento da prática ilícita, de forma que seu conhecimento, em tais hipóteses, pode ser legitimamente presumido. Diversamente, a fraude à quota de gênero não possui efeitos explícitos e perceptíveis no pleito, na medida em que não se reverte em incremento na propaganda eleitoral ou em qualquer tipo de influência direta sobre a vontade do eleitor, e, de regra, não é conhecida, sequer potencialmente, pelos demais candidatos, sendo forjada de forma sigilosa no âmbito da direção partidária ou apenas entre alguns candidatos.

É nítida a diferença na imediatidade do benefício nas hipóteses mencionadas acima: em se tratando de abuso de poder típico, caracterizado por atos como o uso abusivo de recursos financeiros na propaganda eleitoral ou o emprego da autoridade para direcionar o voto de subordinados, a conduta reflete de forma direta no resultado eleitoral, majorando o número de votos obtido por determinado candidato ou permitindo o dispêndio de

\footnotetext{
${ }^{13} \mathrm{O}$ ministro Edson Fachin, em voto vencido, sustentou, em posição que nos parece correta, que os votos obtidos pelos candidatos cassados em decorrência da fraude de gênero deveriam ser considerados nulos, na forma do art. 222 do Código Eleitoral, com o consequente recálculo dos quocientes eleitoral e partidário.
} 
recursos mais expressivos em sua campanha; por outro lado, o benefício advindo com a fraude de gênero, se existente, é apenas indireto ou mediato, ao possibilitar o registro de um número superior de candidatos homens, com a possível modificação favorável no quociente partidário; sendo que, conforme visto, nos termos da lei, apenas o benefício de caráter direto permite que a cassação atinja terceiro que não tenha contribuído com o ilícito eleitoral.

Há que se considerar, também, que, caso se admita que o potencial reflexo na formação do quociente partidário basta para caracterização de benefício direto em favor de todos os candidatos da agremiação política no pleito proporcional, a justificar a ampla cassação de seus registros ou diplomas, por coerência, em praticamente todas as hipóteses de acolhimento da Aije por abuso de poder seria necessário estender a cassação aos demais integrantes do partido político, eis que beneficiados pelo cômputo da votação ilicitamente obtida no quociente partidário, notadamente se adotado o entendimento majoritariamente esposado pelo TSE quando do julgamento do REspe 193-92/PI, no sentido de que os votos dos candidatos cassados após a realização do pleito devem ser computados no cálculo do quociente partidário, na forma do art. 175, $\iint 3^{2}$ e $4^{2}$, do Código Eleitoral.

Ilustrativamente, caso determinado candidato em pleito proporcional incorra em hipótese típica de abuso de poder, utilizando, p. ex., recursos econômicos excessivos em sua campanha para produção de quantidade desmedida de propaganda eleitoral, e sua cassação ocorra somente após o pleito, os votos por ele obtidos, se computados na forma do art. $175, \int 4^{\circ}$, do CE, refletirão favoravelmente no quociente partidário e, nem por isso, se entende que a cassação, nessa hipótese, deve ser estendida aos demais candidatos da agremiação. Nesse sentido, sequer a possível anulação da votação obtida pelo candidato incurso na prática ilícita, na forma do art. 220 do CE, tal como defendido pelo ministro Edson Fachin - a nosso ver com razão - no voto vencido que proferiu no julgamento do REsp 193-2/ PI, afastaria o potencial benefício, tendo em vista que a propaganda eleitoral abusiva veicula, juntamente com o nome e o número do candidato, o emblema e o número do partido político, de modo que pode favorecer, também, a votação na legenda, refletindo igualmente no quociente partidário.

Evidentemente, a adoção de entendimento nesse sentido, com a ampliação do conceito de terceiro beneficiado em todas as hipóteses de abuso de poder, traria grave prejuízo à estabilidade do jogo democrático, que estaria sujeito a sucessivas e drásticas alterações no seu resultado, com 
cassações de chapas inteiras, a cada Aije julgada procedente e, se não deve ser adotado nas hipóteses típicas e expressamente previstas pelo legislador como hipóteses de incidência do preceito sancionatório contido no art. 22, XIV, da LC 64/1990, também não deve, com maior razão, ser adotado na hipótese de fraude à quota de gênero, na qual o próprio cabimento da Aije e das sanções cabíveis nessa espécie de ação eleitoral decorrem, como já visto, de elastério hermenêutico, motivado por questões de cunho instrumental.

Há de se considerar, por fim, que a própria existência de benefício ainda que de natureza indireta - aos demais integrantes da legenda, pela modificação do quociente partidário, é incerta, pois embora a fraude realmente permita o registro de um maior número de candidatos homens, a prática ilícita preenche um determinado número de vagas com candidaturas que, dado seu caráter fraudulento, obterão um número inexpressivo de votos e que, se não houvesse ocorrido a fraude, teriam seu lugar ocupado por candidatas mulheres verdadeiramente engajadas na campanha política e, consequentemente, buscando e conquistando votos que refletiriam positivamente no quociente partidário. Trata-se, assim, de presunção de benefício, que não se compatibiliza com os postulados restritivos do direito eleitoral sancionador.

Nessa linha, o ministro Og Fernandes, no voto vencido proferido no REspe 193-92, para além de não vislumbrar benefício a terceiros, considera que os demais candidatos integrantes do partido, que não tomaram parte no ilícito, são, em verdade, prejudicados pela fraude, na medida em que deixam de obter o auxílio da candidata "laranja" na conquista de votos para o partido político, e bem expõe a incompatibilidade do conceito de benefício exigido pelo art. 22, XIV, da LC 64/1990 para incidência da cassação do mandato com a potencial benesse auferida pelos demais integrantes da legenda em decorrência da fraude:

Em verdade, a meu sentir, os demais candidatos, tidos por beneficiários, nada mais são que outros prejudicados pela fraude. Isso porque, como se sabe, trata-se de eleições proporcionais. O comportamento esperado de todos os candidatos é a obtenção do máximo de votos, seja para se eleger, seja para ajudar no cálculo do quociente eleitoral. Assim, não há benefício concreto para os demais colegas de partido/ coligação. Ainda que se considere a existência de benefício sob o fundamento de as candidaturas "laranjas" viabilizarem o cumprimento da cota de gênero estabelecida no art. 10, \3을 da Lei 9.504/1997, o mero benefício de participar da legenda/coligação não se subsume ao tipo do art. 22, XIV, da LC 64/1990. 
Assim, constata-se que a ampliação do alcance da pena de cassação de mandato em sede de Aije para atingir todos os candidatos integrantes da legenda em que verificada a fraude à quota de gênero é passível de críticas e pode propiciar consequências práticas que vão de encontro ao louvável intuito de aumentar a efetividade da ação afirmativa que se pretende implementar por meio do percentual mínimo de gênero.

\section{Conclusão}

Como visto, a cassação dos demais integrantes de partido político ou coligação em que constatada a fraude ao percentual de gênero, em sede de Aije, passou a ser admitida pela jurisprudência eleitoral após sucessivos elastérios hermenêuticos, inicialmente com a ampliação do conceito de fraude até então adotado pelo TSE, para admissão da análise da matéria em sede de Aime, e, em seguida, para enquadrar essa espécie de fraude dentre as hipóteses legais de cabimento da Aije, atraindo, com isso, a incidência das sanções previstas no art. 22, XIV, da LC 64/1990, dentre as quais a cassação de terceiros beneficiados ${ }^{14}$ pela prática do ato.

A evolução jurisprudencial a esse respeito, com a crescente mitigação do princípio da tipicidade das ações eleitorais, foi norteada pela necessidade de antecipar e garantir a apreciação jurisdicional de tais situações, em prol da normalidade e legitimidade dos pleitos, diante da constatação de que essa espécie de fraude, ordinariamente, somente pode ser constatada após a fase de registro das candidaturas, na qual é aferido o preenchimento da quota de gênero, e que, em sede de Aime, o polo passivo é ocupado apenas por aquele que tenha obtido mandado eletivo apto a ser impugnado, de forma que a candidata "laranja", que, de regra, não é eleita, não poderia ser atingida por meio de tal ação eleitoral. Além disso, considerou-se inoportuno postergar o enfrentamento da matéria para a fase de impugnação ao mandato eletivo, tendo em vista o grande lapso temporal existente entre a fase de registro das candidaturas, quando a fraude ocorre, e a fase de impugnação ao mandato eletivo, que somente tem início nos 15 dias subsequentes à diplomação, sem que exista outro mecanismo processual apto a apurar a fraude neste interregno. Assim, considerou-se necessário admitir o manejo

${ }^{14}$ Como exposto alhures, a própria existência de benefício direto aos demais integrantes da legenda em decorrência da prática fraudulenta nos parece incerta, podendo se falar, no máximo, em benefício indireto ou mediato, consistente na ampliação do número de vagas disponíveis. 
de Aije para enfrentamento da matéria, a fim de evitar verdadeiro "vácuo jurisdicional" acerca do tema, em ofensa ao princípio da inafastabilidade da jurisdição (art. 5, XXXV, da CF/88).

Contudo, conforme demonstrado, é possível que aplicação irrestrita das sanções típicas da Aije, com a ampliação do alcance das sanções decorrentes do lançamento de candidatura fraudulenta para atingir terceiros não diretamente envolvidos no ardil e cassar, na íntegra, as candidaturas da legenda em que verificada a prática ilícita, para além de poder atingir mulheres legitimamente eleitas, pode conduzir à situação fática oposta àquela que se pretendeu prestigiar, ao tornar o lançamento de candidaturas femininas, sobretudo de candidatas que concorrem pela primeira vez e que não sejam previamente conhecidas pelos órgãos de direção do partido político, conduta arriscada e potencialmente danosa às pretensões políticas da agremiação no pleito, criando estímulo para que os partidos políticos, visando minimizar riscos, lancem apenas candidaturas de representantes do sexo feminino já conhecidas e experientes e que cada nova pré-candidata seja submetida a rigoroso escrutínio acerca de suas motivações e da viabilidade de sua candidatura, antes de ser aceita pela agremiação política.

Assim, tem-se que, na prática, as mulheres poderão acabar sendo submetidas a requisito não exigido dos candidatos do sexo masculino, criando-se restrições ainda mais severas ao ingresso e efetiva participação das mulheres na vida política do País e ao surgimento de novas lideranças femininas.

Certamente, a solução ideal para superação desse quadro, que certamente não atende aos fins da ação afirmativa, seria o melhor tratamento legislativo da matéria, tendo em vista que a lei eleitoral não trata de forma específica acerca da fraude à quota de gênero, deixando de indicar claramente a ação eleitoral cabível para sua apuração ou as consequências e sanções aplicáveis na hipótese de sua constatação em momento posterior à fase de registro das candidaturas. Ou seja, o potencial vácuo jurisdicional, que motivou a ampliação das hipóteses de cabimento da Aije para abarcar a matéria, decorre de verdadeiro vácuo legislativo e que deve ser suprido pelo legislador.

Porém, até que se tenha lei dando melhor tratamento à matéria, parece-nos que a solução que melhor atenderia aos fins da ação afirmativa, sem desrespeitar os postulados restritivos do direito eleitoral sancionador, seria a adoção de posição intermediária, com a admissão do manejo da Aije 
para apuração da fraude à quota de gênero, mas restringindo-se o alcance da cassação de terceiros ao número de vagas de candidaturas masculinas cujo registro foi possibilitado pela candidatura feminina fraudulenta ${ }^{15}$, anulando-se a votação obtida pela candidata "laranja" e dos candidatos beneficiados, na forma do art. 220 do Código Eleitoral.

\section{Referências}

BOBBIO, Norberto. et al. Dicionário de Política. Brasília: Universidade de Brasília, 1991.

FUX, Luiz; FRAZÃO, Carlos Eduardo. Novos Paradigmas do Direito Eleitoral. Belo Horizonte: Fórum, 2016.

GOMES, José Jairo. Direito Eleitoral. São Paulo: Atlas, 2018.

LACERDA, Maria Luisa de Medeiros; LUCENA, Alisson Emmanuel de Oliveira. Aportes práticos acerca dos demonstrativos de regularidade dos atos partidários na fase de procedimento de registro de candidatura. Revista Estudos Eleitorais, Recife, v. 2, n. 4, 2018.

LEITE, Crislayne Moura; GUNDIM, Wagner Wilson Deiró. A participação da Mulher na Política Brasileira e a Efetividade das Quotas Partidárias. Revista Eleitoral, Florianópolis, v. 23, n.1, 2019.

RUSSELL, Bertrand. História da Filosofia Ocidental. Rio de Janeiro: Nova Fronteira, 2015.

SANTOS, Poliana Pereira dos; BARCELOS, Júlia Rocha de. GRESTA, Roberta Maia. Debates sobre a Participação Feminina no Parlamento Brasileiro: Sub-representação, Violência e Assédio. Revista Eleitoral, Florianópolis, v. 23, n.1, 2019.

SCHELBAUER, Vinícius Gonçalves. O patriarcado, ações afirmativas e a subrepresentatividade da mulher, Paraná Eleitoral: revista brasileira de direito eleitoral e ciência política, v. 9, n.1, 2020.

Henrique Kurscheidt - Especialista em Direito Processual Civil pelo Instituto de Direito Romeu Felipe Bacellar (2010) e em Filosofia e Teoria do Direito pela Pontifícia Universidade Católica de Minas Gerais (2019). Juiz de Direito no Paraná. Professor no curso de pós-graduação em Direito Aplicado da Escola da Magistratura do Paraná, núcleo Ponta Grossa.

${ }^{15}$ Excluindo-se os candidatos menos votados na lista do partido político, em deferência à vontade popular manifestada nas urnas.

Resenha Eleitoral (Florianópolis), v. 24, n. 2, p. 99-116, 2020 